Journal of Computational Acoustics, Vol. 25, No. 4 (2017) 1799001 (4 pages)

(C) IMACS

DOI: $10.1142 / S 0218396 X 17990016$

\title{
Author Index \\ Volume 25 (2017)
}

Aizenberg, A. M., see Favretto-Cristini, N.

Akhnoukh, J. T., see van der Velden, W. C. P.

Andersen, P. R., see Henríquez, V. C.

Arslan, E., Özyörük, Y. and Çalişkan, M., Numerical Analysis of

One-Dimensional Sound Propagation Through a Duct Containing Water

Droplets

Basse, N. T., see Simurda, M.

Çalışkan, M., see Gül, Z. S.

Çalişkan, M., see Arslan, E.

Chao, Z., see Fangli, N.

Chen, H., see Chen, L.

Chen, L., Marburg, S., Chen, H., Zhang, H. and Gao, H., An Adjoint Operator Approach for Sensitivity Analysis of Radiated Sound Power in Fully Coupled Structural-Acoustic Systems

Chen, L., Wu, S. F., Xu, Y., Lyman, W. D. and Kapur, G., Calculating Blood

Pressure Based on Measured Heart Sounds

Chengzhi, G., see Liufang, F.

Cissello, E., see Riondato, I.

Cristini, P., see Favretto-Cristini, N.

Duan, R., see Yang, K.-D.

Duan, R., see Yang, K.

Duggen, L., see Simurda, M.

Fangli, N., Yong, L., Chao, Z., Jingang, W., Xudong, S. and Juan, W., Acoustic Imaging with Compressed Sensing and Microphone Arrays

Favretto-Cristini, N., Aizenberg, A. M., Ursin, B., Cristini, P. and Tantsereva, A., Analysis of Wave Scattering from a Viscoelastic Layer with Complex Shape

Friard, O., see Riondato, I.

Gamba, M., see Riondato, I.

Gao, B., Wang, N. and Wang, H. Z., Investigation of Sea Surface Effect on

Shallow Water Reverberation by Coupled Mode Method

Gao, H. and Li, S., Improved Integral Formulation for Acoustic Radiation Using Integral Equation of Frequency Averaged Quadratic Pressure

Gao, H., see Chen, L.

Giacoma, C., see Riondato, I.

Gilbert, R. P. and Shoushani, M., The Biot Model for Anisotropic Poro-Elastic

Media: The Viscoelastic Fluid Case

Guist, C., see Langer, P.

Gül, Z. S., Xiang, N. and Çalışkan, M., Diffusion Equation-Based Finite

Element Modeling of a Monumental Worship Space

Guo, S. M., see Su, L.

Guo, X., see Zhang, Q.

He, W., see Zhang, F.

25, 3 (2017) 1750023

25, 3 (2017) 1750010

25, 4 (2017) 1750006

25, 1 (2017) 1650017

25, 4 (2017) 1750005

25, 4 (2017) 1750029

25, 1 (2017) 1650017

25, 4 (2017) 1750027

25, 1 (2017) 1750003

25, 1 (2017) 1750003

25, 3 (2017) 1750014

25, 2 (2017) 1750034

25, 3 (2017) 1750018

25, 3 (2017) 1750023

25, 2 (2017) 1750001

25, 3 (2017) 1750019

25, 4 (2017) 1750005

25, 4 (2017) 1750027

25, 3 (2017) 1750023

25, 3 (2017) 1750018

25, 3 (2017) 1750018

25, 2 (2017) 1750017

25, 1 (2017) 1750004

25, 1 (2017) 1750003

25, 3 (2017) 1750018

25, 3 (2017) 1750012

25, 4 (2017) 1750025

25, 4 (2017) 1750029

25, 2 (2017) 1750026

25, 2 (2017) 1750021

25, 4 (2017) 1850008 
Henríquez, V. C., Andersen, P. R., Jensen, J. S., Juhl, P. M. and Sánchez-Dehesa, J., A Numerical Model of an Acoustic Metamaterial Using the Boundary Element Method Including Viscous and Thermal Losses

Jensen, J. S., see Henríquez, V. C.

Jiang, W., see Liu, X.

Jingang, W., see Fangli, N.

Juan, W., see Fangli, N.

Juhl, P. M., see Henríquez, V. C.

Kapur, G., see Chen, L.

Krause, M., see Langer, P.

Langer, P., Maeder, M., Guist, C., Krause, M. and Marburg, S., More Than Six Elements Per Wavelength: The Practical Use of Structural Finite Element Models and Their Accuracy in Comparison with Experimental Results

Lassen, B., see Simurda, M.

Lee, S., Review: The Use of Equivalent Source Method in Computational Acoustics

Li, H., see Yang, K.-D.

Li, L., see Xu, C.-X.

Li, M., see Meijuan, Y.

Li, Q., see Lv, Z.

Li, S., see Gao, H.

Licheng, L., see Meijuan, Y.

Liu, X., Wu, H. and Jiang, W., Hybrid Approximation Hierarchical Boundary Element Methods for Acoustic Problems

Liufang, F., Peng, L., Xinhua, Z., Shuqing, M. and Chengzhi, G., Vector Ocean Ambient Noise Spectrum Simulation Based on Parabolic Equation Model in Shallow Water

Lv, Z., Qiu, Z. and Li, Q., An Interval Reduced Basis Approach and Its Integrated Framework for Acoustic Response Analysis of Coupled Structural-Acoustic System

Lyman, W. D., see Chen, L.

Ma, L., see $\mathrm{Su}, \mathrm{L}$.

Ma, L., see Zhang, Q.

Ma, Y., see Yang, K.

Maeder, M., see Langer, P.

Marburg, S. and Ochmann, M., Numerical Methods for Vibro-Acoustics and Aeroacoustics

Marburg, S., see Chen, L.

Marburg, S., see Langer, P.

Marburg, S., see Moheit, L.

Meijuan, Y., Licheng, L., Li, M. and Shengming, G., Target Localization Based on Two Broadband Guide Sources

Moheit, L. and Marburg, S., Infinite Elements and Their Influence on Normal and Radiation Modes in Exterior Acoustics

Nakayama, A. and Riquimaroux, H., Sensitivity to High Frequency Communication Sounds in the Inner Ear Enhanced by Selective Attention: Preliminary Findings in Mongolian Gerbils

Ochmann, M., see Marburg, S.

Ochmann, M., see Piscoya, R.

Özyörük, Y., see Arslan, E.

Papale, E., see Riondato, I.

Park, J., see Yang, W.

Peng, L., see Liufang, F.

25, 4 (2017) 1750006

25, 4 (2017) 1750006

25, 3 (2017) 1750013

25, 4 (2017) 1750027

25, 4 (2017) 1750027

25, 4 (2017) 1750006

25, 3 (2017) 1750014

25, 4 (2017) 1750025

25, 4 (2017) 1750025

25, 4 (2017) 1750005

25, 1 (2017) 1630001

25, 2 (2017) 1750001

25, 1 (2017) 1650021

25, 2 (2017) 1750020

25, 3 (2017) 1750009

25, 1 (2017) 1750004

25, 2 (2017) 1750020

25, 3 (2017) 1750013

25, 2 (2017) 1750034

25, 3 (2017) 1750009

25, 3 (2017) 1750014

25, 2 (2017) 1750026

25, 2 (2017) 1750021

25, 3 (2017) 1750019

25, 4 (2017) 1750025

25, 4 (2017) 1702001

25, 1 (2017) 1750003

25, 4 (2017) 1750025

25, 4 (2017) 1650020

25, 2 (2017) 1750020

25, 4 (2017) 1650020

25, 3 (2017) 1750016

25, 4 (2017) 1702001

25, 4 (2017) 1730001

25, 1 (2017) 1650017

25, 3 (2017) 1750018

25, 3 (2017) 1750008

25, 2 (2017) 1750034 
Piao, S.-C., see Xu, C.-X.

Piscoya, R. and Ochmann, M., Acoustical Green's Function and Boundary

Element Techniques for 3D Half-Space Problems

Qiu, Z., see Lv, Z.

Riondato, I., Cissello, E., Papale, E., Friard, O., Gamba, M. and Giacoma, C., Unsupervised Acoustic Analysis of the Vocal Repertoire of the Gray-Shanked Douc Langur (Pygathrix cinerea)

Riquimaroux, H., see Nakayama, A.

Ross Chapman, N., see Taroudakis, M.

Rouseff, D., see Zhao, Z. D.

Sánchez-Dehesa, J., see Henríquez, V. C.

Shang, E. C., see Zhao, Z. D.

Shengming, G., see Meijuan, Y.

Shoushani, M., see Gilbert, R. P.

Shuqing, M., see Liufang, F.

Simurda, M., Lassen, B., Duggen, L. and Basse, N. T., A Fourier Collocation Approach for Transit-Time Ultrasonic Flowmeter Under Multi-Phase Flow Conditions

Smaragdakis, C., see Taroudakis, M.

Soboleva, O. N., Modeling of Propagation of Acoustic of Waves in Multiscale Media with Lognormal Distribution of Parameters

Su, L., Ma, L. and Guo, S. M., Influence of Sound Speed Profile on Source

Localization at Different Depths

Tantsereva, A., see Favretto-Cristini, N.

Taroudakis, M., Smaragdakis, C. and Ross Chapman, N., Denoising Underwater Acoustic Signals for Applications in Acoustical Oceanography

Ursin, B., see Favretto-Cristini, N.

van der Velden, W. C. P., Akhnoukh, J. T. and van Zuijlen, A. H., Low-Order

Finite-Volume Based Riemann Solver for Application to Aeroacoustic

Problems

van Zuijlen, A. H., see van der Velden, W. C. P.

Wang, H. Z., see Gao, B.

Wang, N., see Gao, B.

Wang, S., Far-Field Performances Prediction of High Frequency Projectors Using Secondary Source Array Method

$\mathrm{Wu}$, H., see Liu, X.

Wu, S. F., see Chen, L.

Xiang, N., see Gül, Z. S.

Xiao, P., see Yang, K.

Xinhua, Z., see Liufang, F.

Xu, C.-X., Piao, S.-C., Yang, S.-E., Zhang, H.-G. and Li, L., This Submission is for Special Issue on Underwater Acoustics: Perfectly Matched Layer

Technique for Parabolic Equation Models in Ocean Acoustics

Xu, Y., see Chen, L.

Xudong, S., see Fangli, N.

Yang, K., Xiao, P., Duan, R. and Ma, Y., Bayesian Inversion for Geoacoustic

Parameters from Ocean Bottom Reflection Loss

Yang, K.-D., Li, H., Duan, R. and Yang, Q.-L., Analysis on the Characteristic of Cross-Correlated Field and Its Potential Application on Source

Localization in Deep Water

Yang, Q.-L., see Yang, K.-D.

Yang, S.-E., see $\mathrm{Xu}$, C.-X.
25, 1 (2017) 1650021

25, 4 (2017) 1730001

25, 3 (2017) 1750009

25, 3 (2017) 1750018

25, 3 (2017) 1750016

25, 2 (2017) 1750015

25, 2 (2017) 1750011

25, 4 (2017) 1750006

25, 2 (2017) 1750011

25, 2 (2017) 1750020

25, 3 (2017) 1750012

25, 2 (2017) 1750034

25, 4 (2017) 1750005

25, 2 (2017) 1750015

25, 1 (2017) 1750007

25, 2 (2017) 1750026

25, 3 (2017) 1750023

25, 2 (2017) 1750015

25, 3 (2017) 1750023

25, 3 (2017) 1750010

25, 3 (2017) 1750010

25, 2 (2017) 1750017

25, 2 (2017) 1750017

25, 2 (2017) 1750002

25, 3 (2017) 1750013

25, 3 (2017) 1750014

25, 4 (2017) 1750029

25, 3 (2017) 1750019

25, 2 (2017) 1750034

25, 1 (2017) 1650021

25, 3 (2017) 1750014

25, 4 (2017) 1750027

25, 3 (2017) 1750019

25, 2 (2017) 1750001

25, 2 (2017) 1750001

25, 1 (2017) 1650021 
Yang, W. and Park, J., Attenuation of Sounds in a Pipe with Shear Flow Using Layered Metamaterials

25, 3 (2017) 1750008

Yang, X. and Zhu, P., Reservoir Prediction Under Control of Sedimentary Facies

25, 3 (2017) 1750022

25, 4 (2017) 1750027

Zhang, F., He, W. and Zhong, J., Nonlinear Distortion Characteristic Analysis for the Finite Amplitude Sound Pressures in the Pistonphone

Zhang, H., see Chen, L.

Zhang, H.-G., see Xu, C.-X.

Zhang, Q., Guo, X. and Ma, L., The Research of the Characteristics of the Ocean Ambient Noise Under Varying Environment

25, 4 (2017) 1850008

25, 1 (2017) 1750003

25, 1 (2017) 1650021

Zhao, Z. D., Shang, E. C. and Rouseff, D., The Comparison of Bottom

Parameter Inversion in Geoacoustic Space and in $(P, Q)$ Space

Zhong, J., see Zhang, F.

Zhu, P., see Yang, X.

25, $2(2017) 1750021$

25, 2 (2017) 1750011

25, 4 (2017) 1850008

25, 3 (2017) 1750022 